\title{
A educação a distância na autoavaliação da Universidade Federal de Goiás - um estudo bibliográfico e documental ${ }^{1}$
}

\author{
Flávia Magalhães Freire ${ }^{2}$ \\ Wendy Caldeira de Souza ${ }^{3}$ \\ Daniela da Costa Britto Pereira Lima ${ }^{4}$
}

\section{Resumo}

Este estudo busca compreender como a educação a distância (EaD) é representada na autoavaliação institucional na Universidade Federal de Goiás (UFG), a partir da análise de instrumentos avaliativos. A pesquisa desenvolvida é do tipo qualitativa, bibliográfica e documental. A coleta de dados se deu por meio dos documentos disponibilizados pela UFG, por meio da Comissão de Avaliação Institucional (Cavi), em seu site. O período pesquisado engloba os anos de 2006 a 2018. O resultado indica que o desenvolvimento da institucionalização da EaD no âmbito da Universidade ainda está em construção, uma vez que a autoavaliação realizada não contempla as suas especificidades, dificultando o diagnóstico e aprimoramento da modalidade.

Palavras-chave: Educação a Distância; Autoavaliação Institucional; Universidade Federal de Goiás.

\section{Distance education in the self-assessment of Federal University of Goiás - a bibliographic and documentary} study

\section{Abstract}

This study seeks to understand how distance education is represented in institutional self-assessment at the Federal University of Goiás (UFG), based on the analysis of assessment instruments. The research developed is qualitative, bibliographic and documentary. Data collection took place through the documents made available by UFG, through the Institutional Evaluation Commission (Cavi), on its website. The surveyed period encompasses the years 2006 to 2018. The result indicates that the development of the institutionalization of distance education at the University is still under construction, since the self-assessment carried out does not include its specificities, making it difficult to diagnose and improve the modality.

Keywords: Distance Education; Institutional Self-Assessment; Federal University of Goias.

\section{Introdução}

O objetivo desta pesquisa é identificar e discutir de que maneira a educação a distância (EaD), a partir do questionário de autoavaliação de 2016, passou a ser representada no Relatório de Autoavaliação Institucional da UFG [2015-2017]. A abordagem qualitativa foi o método

\footnotetext{
${ }^{1}$ Essa pesquisa faz parte de pesquisa financiada pelo Conselho Nacional de Desenvolvimento Científico e Tecnológico (CNPq). Esse trabalho é fruto de dissertação e pesquisa de iniciação científica.

2 Universidade Federal de Goiás, Goiânia, flaviamf.ead@gmail.com.

${ }^{3}$ Universidade Federal de Goiás, Goiânia, wendycaldeira0@gmail.com.

${ }^{4}$ Universidade Federal de Goiás, Goiânia, daniela_lima@ufg.br.
} 
utilizado para desenvolver o presente estudo, que

ocasionalmente se utilizou, também, de dados quantitativos para as análises realizadas. Segundo Silva e Menezes (2001), ao longo da pesquisa qualitativa identifica-se a necessidade de uma relação entre o mundo real e o sujeito, que, dessa forma, poderá ter acesso ao fenômeno pesquisado. Esse contato possibilitará a inserção do fenômeno dentro de seu contexto, descrevendo e caracterizando-o.

A investigação foi de caráter bibliográfico e documental, a partir da análise dos instrumentos de autoavaliação da UFG, tendo como base a regulamentação atual que rege a avaliação no Brasil - Lei do Sistema Nacional de Avaliação da Educação Superior (Sinaes), Lei n.10.861, de 14 de abril de 2004 -, além de outros documentos norteadores, sempre evitando a generalização de resultados. As fontes de coleta de dados foram os documentos disponibilizados pela UFG por meio da Comissão de Avaliação Institucional/Comissão Própria de Avaliação (CAVI/CPA). O período pesquisado foi de 2006 a 2018.

Cabe salientar que, para Lakatos e Marconi (2003, p.158), “a pesquisa bibliográfica é um apanhado geral sobre os principais trabalhos já realizados, revestidos de importância, por serem capazes de fornecer dados atuais e relevantes relacionados com o tema". Os autores ainda afirmam que a pesquisa documental é caracterizada como uma complexa fonte de dados, que está restrita a documentos, escritos ou não. Esses são nomeados como fontes primárias e secundárias (LAKATOS; MARCONI, 2003).

Como parte da pesquisa, com o objetivo de analisar as perspectivas de estudo a respeito da autoavaliação institucional na educação a distância, foi realizado primeiramente um levantamento bibliográfico em plataformas eletrônicas no período entre os anos de 2006 a 2016. As buscas foram realizadas na Biblioteca Digital Brasileira de Teses e Dissertações (BDTD); nas revistas e/ou periódicos que tratam de avaliação com Qualis A, Ensaio - Avaliação e Políticas Públicas em Educação, Avaliação: Revista da Avaliação da Educação Superior, Estudos em Avaliação Educacional; nas revistas e/ou periódicos que tratam de educação a distância Qualis B4 e B5 - Revista EDaPECI: Educação a Distância e Práticas Educativas Comunicacionais e Interculturais e Revista Educação a Distância. Além disso, foram incluídos o site da Biblioteca Eletrônica SciELO (Scientific Electronic Library Online) e o Google Acadêmico.

O período de busca foi entre os anos de 2006 a 2016. Visto que a Lei no 10. 861, que institui o Sistema Nacional de Avaliação da Educação Superior (Sinaes) e o processo de avaliação 


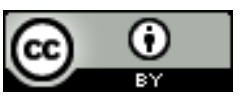

institucional
ARTIGO

DOI: https://doi.org/10.24933/horizontes.v39i1.937 nas instituições brasileiras foi

promulgada no ano de 2004, considerou-se que no ano de 2006, supostamente, haveria um maior número de publicações. Os descritores utilizados foram "educação a distância", "cursos a distância" e "autoavaliação institucional". No entanto, posteriormente, foram acrescentados "avaliação institucional", "ensino superior" e "avaliação" com o intuito de aumentar a quantidade de trabalhos selecionados.

Após a análise dos trabalhos encontrados nas plataformas digitais, apenas treze foram selecionados por atenderem aos critérios estabelecidos e terem relação com a autoavaliação institucional na educação a distância. No que diz respeito aos resultados, os dados do levantamento apontam que grande parte das produções do tema em questão resultam de artigos, com maior quantidade de publicações no ano de 2012, embora tenha um amplo percurso histórico.

Ademais, grande parte das pesquisas analisadas possui como foco principal a avaliação de uma instituição em sua totalidade. Em contrapartida, a minoria das publicações analisa apenas um curso específico de uma determinada instituição, além do envolvimento de temáticas como regulamentações, políticas, metodologias de autoavaliação institucional, referenciais do MEC, dentre outras. Já em relação à quantidade de estudos por regiões, foi possível constatar que a Região Sul possui a maior quantidade de publicações no período pesquisado, chegando a $36 \%$. No entanto, as regiões Norte e Nordeste possuem uma grande inferioridade às demais regiões, sendo que dos trabalhos selecionados, nenhum foi localizado na Região Norte e apenas $7 \%$ no Nordeste.

A partir do que foi realizado no levantamento, cabe ressaltar o quanto é preciso estudar e pesquisar no tocante à autoavaliação das instituições no Brasil, pois além de influenciar no aprimoramento destas, permite o reconhecimento do seu papel enquanto instituição (SOUZA; BORGES; LIMA, 2021).

Assim, este artigo apresenta inicialmente o referencial teórico a respeito da educação a distância e da autoavaliação institucional, para posteriormente apresentar a autoavaliação na Universidade Federal de Goiás, o lugar da EaD nessa autoavaliação por meio de seus documentos e instrumentos e, por fim, suas considerações finais.

\section{A educação a distância no Brasil}


A educação a distância (EaD) é uma modalidade de ensino que oferece um processo de aprendizagem mediado por recursos tecnológicos que possibilitam uma integração entre o aluno e o professor, de tal forma que, mesmo separados fisicamente, estabelecem uma relação pedagógica e de forma eficiente. Segundo Maia e Mattar (2007), ela perpassa todos os níveis de ensino, desde a educação básica até o ensino superior, passando também por cursos técnicos e tecnológicos, constituindo-se assim em objeto de estudos de pesquisadores.

A EaD tem avançado e se consolidado cada vez mais no Brasil, no entanto, para que houvesse a sua construção e organização enquanto modalidade de ensino, ela teve um amplo histórico em sua legislação. Pela primeira vez, na Lei de Diretrizes e Bases da Educação Nacional (LDB) $\mathrm{n}$ - 9.394, em 20 de dezembro de 1996, foi regulamentada como uma modalidade que atravessa todos os níveis da educação, conforme disposto no art. 80: "O Poder Público incentivará o desenvolvimento e a veiculação de programas de ensino a distância, em todos os níveis e modalidades de ensino, e de educação continuada" (BRASIL, 1996).

Além disso, atualmente, a regulamentação da EaD possui seus fundamentos regidos pela Resolução no 1 do Conselho Nacional de Educação (CNE), de 11 de março de 2016, que estabelece as diretrizes e normas para oferta de cursos na modalidade a distância, a partir da Portaria do MEC no 1.428, de 28 de dezembro de 2018, a qual dispõe sobre a oferta da modalidade a distância em disciplinas presenciais e autoriza a possibilidade dessa utilização de até 40\%. E a Portaria MEC no 2.117, de 06 de dezembro de 2019, que dispõe sobre a oferta de carga horária na modalidade a Distância, em cursos de graduação presenciais ofertados por Instituições de Educação Superior (IES) pertencentes ao Sistema Federal de Ensino até o limite de $40 \%$ da carga horária total do curso.

Destacamos que a Portaria MEC no 1.428, de 28 de dezembro de 2018, é válida para todas as IES, e a Portaria MEC no 2.117, de 06 de dezembro de 2019, está direcionada para as instituições federais. Em seu artigo 10, lê-se: “Fica revogada a Portaria MEC no 1.428, de 28 de dezembro de 2018" (BRASIL, 2019). Assim, deixamos em aberto o questionamento: qual das Portarias está regulamentando a situação das instituições privadas?

Ademais, o Decreto № 9.057, de 25 de maio de 2017, que regulamenta o art. 80ㅇ da LDB 9.394/1996, em seu art. 1ำ, defende o conceito de educação a distância como "modalidade educacional na qual a mediação didático-pedagógica nos processos de ensino e aprendizagem

Periódico Horizontes - USF - Itatiba, SP - Brasil - e021058 
informação e comunicação, [...] políticas de acesso, com acompanhamento e avaliação compatíveis" (BRASIL, 2017a, p.1). Por fim, a Portaria no 11, de 20 de junho de 2017, que estabeleceu as normas para o credenciamento de instituições e a oferta de cursos superiores a distância.

Portanto, a partir dos conceitos de EaD expostos até aqui e o que LIMA (2014) apresenta, entenderemos ao longo deste artigo como educação a distância:

[...] a EaD é uma prática social- educativa-dialógica de um trabalho coletivo, de autoria e colaborativo, articulada para o desenvolvimento de uma arquitetura pedagógica e de gestão, integrada ao uso significativo das tecnologias de informação e comunicação, voltada para a formação crítica, autonoma e emancipadora (LIMA, 2014, p.59).

A educação a distância tem sido utilizada em diversos níveis educacionais e adotada por muitas instituições. Nesse sentido, o Censo da Educação Superior 2018 (INEP, 2019) aponta os seguintes números: um total de 2.056.511 matriculados em cursos a distância no Brasil, sendo assim distribuídos: 11.460 na região Norte do país; 101.940 na região Nordeste; 810.841 na região Sudeste; 945.658 na região Sul e 186.612 na região Centro-Oeste. No total são 3.177 cursos ofertados no ano de 2018, somando 273.873 concluintes em todo o Brasil.

Logo, com o número de matrículas na casa dos milhões de alunos, é fundamental que se estabeleçam critérios de avaliação para as instituições que oferecem essa modalidade educacional, buscando avaliar tanto a própria instituição quanto os seus alunos, docentes e servidores, para que assim possam ofertar um ensino efetivo e de qualidade.

\section{Autoavaliação institucional}

A avaliação institucional é um instrumento utilizado pelas instituições de ensino superior com o intuito de transformar e aprimorar a qualidade da oferta de ensino, e diante de seus resultados, torna-se possível refletir e promover mudanças na organização e desempenho dessas instituições. Além disso, ela é responsável por grandes mudanças, desde os currículos à gestão e práticas pedagógicas. De acordo com Sobrinho (2010, p.195), 

implementação das reformas educacionais. Produz mudanças nos currículos, nas metodologias de ensino, nos conceitos e práticas de formação, na gestão, nas estruturas de poder, nos modelos institucionais, nas configurações do sistema educativo, nas políticas e prioridades da pesquisa, nas noções de pertinência e responsabilidade social.

No Brasil, a avaliação institucional teve início na década de 1970, com a instituição da política de avaliação da Pós-Graduação, focada em cursos de mestrado e doutorado, pela Coordenação de Aperfeiçoamento de Pessoal de Nível Superior (CAPES). Em 1983, houve o princípio do processo de avaliação de cursos de graduação pelo Ministério da Educação (MEC), do Programa de Avaliação da Reforma Universitária (PARU), que teve duração de apenas um ano. Já no início da década de 1990, algumas instituições começaram a adotar o processo de autoavaliação, contribuindo com a construção do Programa de Avaliação Institucional das Universidades Brasileiras (PAIUB), apoiado pela Secretaria de Educação Superior (SESU/MEC), de 1993 a 1994. Mais tarde, em 1996, como procedimentos avaliativos, criou-se o Exame Nacional de Cursos (ENC), conhecido como "Provão", além da Avaliação das Condições de Ensino (ACE) e a Avaliação para credenciamento de IES privadas. Entretanto, nenhum teve uma vigência mais longa ou ampla. (POLIDORI; MARINHO-ARAUJO; BARREYRO, 2006).

Somente no ano de 2004, durante o governo de Luiz Inácio Lula da Silva (2003-2010), foi promulgada a Lei no 10.861, instituindo o Sistema Nacional de Avaliação da Educação Superior (Sinaes) e, consequentemente, tornando-se obrigatório o processo de avaliação institucional em todas as instituições de ensino superior do Brasil. O Sinaes tem como objetivo a melhoria na qualidade da educação superior, promovendo a avaliação das instituições, seus cursos e o desempenho de seus discentes, conforme disposto em seu art. $2^{\circ}$ :

Art. 2o O SINAES, ao promover a avaliação de instituições, de cursos e de desempenho dos estudantes, deverá assegurar:

I - avaliação institucional, interna e externa, contemplando a análise global e integrada das dimensões, estruturas, relações, compromisso social, atividades, finalidades e responsabilidades sociais das instituições de educação superior e de seus cursos;

II - o caráter público de todos os procedimentos, dados e resultados dos processos avaliativos;

III - o respeito à identidade e à diversidade de instituições e de cursos;

IV - a participação do corpo discente, docente e técnico-administrativo das instituições de educação superior, e da sociedade civil, por meio de suas 
Portanto, de acordo com esse preceito as avaliações devem ocorrer de forma interna e externa nas instituições, sendo internamente por meio da autoavaliação organizada por uma comissão da instituição responsável por realizar tal função, a Comissão Própria de Avaliação (CPA), e externamente por comissões nomeadas pelo Instituto Nacional de Estudos e Pesquisas Educacionais Anísio Teixeira (Inep).

Sobre a execução dessas duas modalidades de avaliação institucional, Depresbiteris (2005) defende que

\begin{abstract}
As ações de avaliação interna e externa devem ser realizadas de forma combinada e complementar, devendo prevalecer, em ambas, plena liberdade de expressão e busca de rigor e justiça. A instituição deve esforçar-se para motivar a comunidade e para envolver vários de seus setores a participarem dos processos avaliativos. A avaliação externa pode ajudar a suplantar certas ilusões de percepção interna, decorrentes de rotinas, o que impede uma visão crítica fundamentada. Deve-se evitar, igualmente, o uso da autoavaliação como uma justificativa, uma defesa daquilo que se está desenvolvendo e não como uma projeção futura de melhoria (DEPRESBITERIS, 2005, p.10).
\end{abstract}

Para efeitos deste estudo, será enfatizado o processo de avaliação interna, com ênfase na autoavaliação institucional, visto que se trata de um instrumento fundamental em uma instituição. Portanto, a autoavaliação é o processo de autoconhecimento de uma instituição, é o procedimento em que ela constrói um conhecimento sobre a sua própria realidade, seu corpo docente, discente, técnico administrativo e toda a comunidade acadêmica, traçando um diagnóstico e buscando uma melhoria na qualidade de ensino. Conforme afirmam Galdino (2011) e Sobrinho (2008),

A avaliação interna deve ser um processo contínuo, pelo qual uma instituição constrói conhecimento sobre sua própria realidade, buscando compreender os significados do conjunto das suas atividades para melhorar a qualidade educativa e alcançar maior relevância social. Para tanto, sistematiza informações, analisa coletivamente os significados de suas realizações, desvenda formas de organização, administração e ação, identifica pontos fracos, bem como pontos fortes e potencialidades e estabelece estratégias de superação de problemas (GALDINO, 2011, p.1).

Consiste em um amplo balanço que cada instituição deve fazer para conhecerse mais profundamente, refletir sobre suas responsabilidades, seus problemas 

melhorar a qualidade em todas as dimensões institucionais e educativas (SOBRINHO, 2008, p.819).

A autoavaliação, além de levantar dados, é uma ferramenta capaz de mediar as transformações e mudanças das instituições, pois colaboram para um processo de autoconhecimento e, consequentemente, de reconstruções, buscando melhorias em sua estrutura, gestão, ensino, dentre outras. Galdino (2011) explicita que:

A autoavaliação não deve ser considerada como controle institucional, mas como mediadora de um processo de tomada de consciência, individual e coletiva, que leva a instituição a uma autocrítica e (re)define seus caminhos com vistas à (trans)formação e melhora contínua da sua realidade, associada à sua missão (GALDINO, 2011, p.14).

Em se tratando da educação a distância, aqui defendida como uma modalidade de ensino que possui suas especificidades e necessidades, o seu processo de autoavaliação institucional deve ocorrer de forma separada e distinta da modalidade presencial, garantindo, assim, uma avaliação de qualidade. Sobre as especificidades da EaD, Moore e Kearsley (2007) afirmam:

Empregar [...] tecnologias depende, por sua vez, da utilização do tipo de técnicas de criação e comunicação específicas dessas tecnologias e diferentes daquelas que os professores normalmente aplicam em sala de aula. Usar essas tecnologias e técnicas para a educação a distância exige mais tempo, planejamento e recursos financeiros. Ser um aluno a distância também é diferente; a pessoa precisa ter aptidões distintas para o estudo e habilidades de comunicação diferentes; comumente, esse modo de educar agrada a um setor da população diferente daquele que frequenta escolas tradicionais (MOORE; KEARSLEY, 2007, p.1).

Pensando ainda nessas especificidades da EaD, Freire (2018) aponta características da autoavaliação institucional voltadas para a educação a distância. Devem ser considerados aspectos que englobem participação, estrutura física, diferenciação entre modalidades presencial e a distância, representação, entre outros, em um constante processo de autoconhecimento da instituição.

O primeiro ponto a ser destacado é a orientação da autoavaliação institucional da EaD, para que a instituição entenda o processo desenvolvido por ela mesma, podendo assim 
funcionamento institucional, assim como a responsabilidade social. Em segundo lugar, é fundamental que a avaliação seja contínua, democrática, participativa e global (FREIRE, 2018).

As ferramentas de participação e análise de dados devem considerar as especificidades da educação a distância. Aspectos como tutoria, polos e interação entre discentes e docentes devem estar representados de forma explícita no momento da avaliação (FREIRE, 2018). Isso é fundamental para que as melhorias para a modalidade sejam pensadas de acordo com suas reais necessidades e não apenas como um apêndice da educação presencial, como muitas vezes acontece.

Com esses preceitos em mente, deve haver pelo menos um representante para a educação a distância dentro das Comissões Próprias de Avaliação (CPAs). Essas devem, por sua vez, trabalhar em etapas. Em primeiro lugar, deve acontecer a preparação, em segundo, elaboração da proposta e planejamento, em terceiro, o desenvolvimento e, por último, a consolidação da avaliação. Essa avaliação deve, também, incluir análises sobre o polo EaD no contexto da autoavaliação (FREIRE, 2018), pois este é parte essencial da educação a distância e sua estrutura e equipe podem acontecer em um contexto totalmente distanciado do da instituição, apesar de ainda fazer parte dela.

Esse processo contínuo de autoavaliação deve considerar, de acordo com os Referenciais de Qualidade para a Educação a Distância, uma ampla conjuntura: instalações físicas; aspectos de organização didático-pedagógica; e corpo docente, corpo de tutores, corpo técnico-administrativo e discentes. Enfim, o Freire (2018, p.119) destaca que a autoavaliação institucional da EaD deve reverter "[...] os dados sobre EaD resultantes da autoavaliação em objetos de análise e tomada de decisão, possibilitando maior entendimento sobre os funcionamentos e processos da modalidade".

Sendo assim, como previsto no objetivo desta pesquisa, no próximo item será analisado como se dá o processo de autoavaliação da educação a distância na Universidade Federal de Goiás, sobretudo, a sua representação e institucionalização na instituição.

\section{A autoavaliação na UFG}

Até 2018, período que engloba a presente pesquisa, o órgão responsável pela autoavaliação institucional da Universidade Federal de Goiás era a Comissão de Avaliação Institucional (Cavi/UFG). Ela foi criada em 1994, mesmo ano em que houve o primeiro processo 
Comissão Própria de Avaliação (CPA), conforme previsto na Lei do Sinaes, de 2004, em seu art. 110: “Cada instituição de ensino superior, [...] constituirá Comissão Própria de Avaliação - CPA, [...] com as atribuições de condução dos processos de avaliação internos da instituição, de sistematização e de prestação das informações solicitadas pelo INEP [...]" (BRASIL, 2004). Tendo como objetivo "instituir na UFG uma cultura de avaliação subsidiando de modo pleno a gestão acadêmica, rumo à potencialização e desenvolvimento do desempenho institucional" (UFG, 2016b, p.23).

O art. 3 da Resolução CONSUNI no 14/2009, de 22 de maio de 2009, que institui a CAVI, prevista no Estatuto e Regimento da Universidade como CPA, define que a Comissão tem como responsabilidade:

I - conduzir o processo de avaliação interna da instituição (autoavaliação), instituída pelo Sistema Nacional da Avaliação da Educação Superior - SINAES, planejando, organizando e executando as atividades, mantendo o interesse pela avaliação, sensibilizando a comunidade e fornecendo assessoramento aos diferentes setores da UFG; II - conduzir a sistematização e a prestação das informações solicitadas pelo Instituto Nacional de Estudos e Pesquisas Educacionais - INEP durante o processo de avaliação; III - prestar contas de suas atividades ao Conselho Universitário - CONSUNI da UFG, apresentando relatórios, pareceres e eventualmente recomendações; IV -divulgar amplamente suas atividades à comunidade acadêmica (UFG, 2009).

A Comissão de Avaliação Institucional tem como membros servidores docentes, técnicoadministrativos, estudantes e representantes da sociedade civil nomeados pelo reitor. De acordo com a Portaria no 5.126, de 6 de setembro de 2016, fazem parte da Comissão o total de treze docentes, onze técnico-administrativos, seis discentes e cinco representantes da sociedade civil. No entanto, não são especificadas as funções que cada um desempenha e, consequentemente, se há ou não representantes da educação a distância.

Não obstante, Freire (2018), em uma entrevista com membros da Cavi, apresenta que há um representante da EaD no corpo docente da Comissão, mas de forma não oficial, pois todos os membros são identificados apenas como representantes docentes. Segundo entrevistas realizadas por Freire (2018), esse docente desempenha o papel apenas desde 2015 e seu trabalho não é voltado de forma específica para a EaD. Assim, compreendemos que, no âmbito da avaliação institucional da $\mathrm{EaD}$, não existe nenhum docente na Comissão que esteja 
educação a distância de maneira particular.

Além disso, não há um processo de autoavaliação na UFG a partir de 2016 que considere todas as peculiaridades, aspectos organizacionais e estruturais da educação a distância, sendo possível concluir que a modalidade ainda está em processo de ocupar o seu lugar na instituição, sobretudo na avaliação institucional.

Também não existe, na UFG, um processo de autoavaliação no âmbito da Cavi que compreenda as especificidades de organização didático-pedagógica; corpo docente, corpo de tutores, corpo técnico-administrativo e discentes; e instalações físicas voltadas para a modalidade a distância. Assim, considera-se que no aspecto da estrutura organizacional, a EaD ainda está em vias de ser desenvolvida nas práticas de avaliação institucional da UFG (FREIRE, 2018, p.157-158).

Dessa maneira, como sendo uma de suas funções no processo de autoavaliação institucional, a Cavi se utiliza de questionários como instrumentos de avaliação. A organização dos dados coletados através desses questionários resulta em relatórios publicados pela Comissão em ciclos, apresentando, assim, o diagnóstico da instituição. A seguir, serão analisados esses instrumentos utilizados na avaliação interna da UFG.

\section{Os instrumentos de autoavaliação e a EaD na UFG}

Os instrumentos de avaliação disponibilizados pela Cavi em seu site constam a partir do ano de 2009, sendo o seu período de permanência entre 2009 a 2015. Os participantes para a coleta de dados desse processo autoavaliativo foram os professores, discentes e técnicoadministrativos. Os questionários desse período são: Roteiro de Entrevista do grupo de enfoque Docentes e Técnicos-Administrativos; Roteiro de Entrevista do grupo de enfoque Discente; Roteiro da Entrevista do grupo de enfoque da avaliação externa; Questionário a ser respondido pelas Unidades/Campi/Núcleos; Questionário a ser respondido pelos estudantes do Centro de Ensino e Pesquisa Aplicada à Educação; Questionário a ser respondido pelos estudantes de Graduação; Questionário a ser respondido pelos estudantes de Pós-Graduação; Questionário a ser respondido pelos estudantes de Graduação na modalidade à distância; Questionário a ser respondido pelos estudantes de Pós-Graduação Lato Sensu na modalidade a distância; 
estudantes.

No que diz respeito à educação a distância, os seus questionários (de 2009 a 2015) são separados da modalidade presencial, no entanto, apenas dois a possuem como objeto principal (Questionário a ser respondido pelos estudantes de Graduação na modalidade a distância e o Questionário a ser respondido pelos estudantes de Pós-Graduação Lato Sensu na modalidade a distância). Esses questionários, que contemplam algumas especificidades da EaD, são destinados aos alunos de graduação e pós-graduação, possuindo como foco os aspectos pedagógicos e de infraestrutura. As questões presentes nos questionários são semelhantes, porém adaptadas de acordo com cada nível educacional.

Nesses questionários, de 2009 a 2015, os elementos da EaD que foram avaliados dizem respeito aos aspectos pedagógicos, como os planos de ensino dos professores, o material utilizado, a dinâmica das aulas, o ambiente virtual de aprendizagem, equipe pedagógica (professores, coordenador, orientador e tutores), se há ou não projetos de pesquisa, ensino e extensão, dentre outros. Além disso, os aspectos de infraestrutura também foram avaliados, como os polos e sua estrutura quanto a laboratórios, equipamentos, bibliotecas e material didático oferecido.

No ano de 2015, devido a mudanças no ciclo avaliativo, que passou a ser trienal, houve alterações, de forma que em 2016 foram utilizados quatro novos instrumentos de coleta de dados, disponibilizados no Portal UFGnet, no Sistema Integrado de Gestão de Atividades Acadêmica - Módulo Avaliação (UFG, 2017b). São eles: Instrumento de Autoavaliação Institucional; Instrumento de Avaliação da Turma pelo Docente; Instrumento de Autoavaliação do Estudante e Instrumento de Avaliação do Docente pelos Estudantes, sendo os dois últimos que englobam o ensino a distância. Como os instrumentos analisados anteriormente, eles foram respondidos por estudantes, professores e técnico-administrativos, porém, se diferenciando ao realizar os mesmos formulários de avaliação para a modalidade presencial e a distância, sem distinções e atribuindo notas de zero a dez.

Os elementos da EaD avaliados no período anterior já não se fazem presentes neste período. Os questionários não estão adaptados para as diferentes modalidades e não possuem questões voltadas de maneira específica para a educação a distância. As perguntas envolvem a avaliação da postura acadêmica do discente, como se participa das aulas, se há o cumprimento das atividades propostas pelo professor ou tutor, se dedicam um tempo para estudos, dentre 
pelos Estudantes, tratam do funcionamento das aulas, metodologias utilizadas, plano de ensino etc. Portanto, é perceptível o quanto existe uma visão não diferencial a respeito da educação a distância, ignorando as especificidades que a diferenciam da modalidade presencial, conforme defendemos no decorrer deste estudo.

Posteriormente, no ano de 2017, os instrumentos de Autoavaliação do Estudante e Avaliação do Docente pelos Estudantes permaneceram iguais, somente os destinados aos docentes e técnico-administrativos se modificaram, em que "foi disponibilizado o questionário de Avaliação Institucional relativo à gestão e as condições de trabalho, além do questionário de Avaliação das Turmas" (UFG, 2017a, p.1).

Em uma possível tentativa de equiparar as modalidades tornando-as igualmente importantes dentro da instituição, as especificidades da EaD, a partir de 2016, passaram então a não ser mais consideradas em separado da avaliação da educação presencial. As novas mudanças nos questionários de autoavaliação possuem como foco somente aspectos gerais da instituição, como de gestão, infraestrutura, planejamento e materiais, sendo disponibilizados apenas para os docentes e técnico-administrativos.

Somente no Instrumento de Avaliação Docente pelos Estudantes, nesses dois anos, em sua primeira questão que avalia se o docente "3.1.1 comparece às aulas/orientações/chats sob sua responsabilidade" (UFG, 2017a, p.52)., abrange especificidades da educação a distância. E no ano de 2017, acrescentando as disciplinas de orientação, mas também somente a questão do comparecimento. Os chats e orientações fazem parte da EaD, mas não são as únicas ferramentas com as quais ela trabalha. É preocupante que apenas alguns aspectos rasos da modalidade estejam sendo avaliados e considerados, quando a plataforma virtual de aprendizagem oferece mecanismos diversos que são certamente utilizados pelos professores, assim como diferentes abordagens de ensino e avaliação de alunos - nenhum desses aspectos considerados no âmbito da avaliação institucional.

Ainda a esse respeito, Freire (2018), levanta as seguintes questões a respeito da autoavaliação institucional da EaD na UFG:

Os questionários aplicados entre 2009 e 2015 respeitavam as especificidades da $E a D$, enquanto os instrumentos utilizados a partir de 2016 já não mais possibilitam essa função. Como compreender quais as necessidades da 
que momento da interpretação dos dados levantados pelos questionários a modalidade presencial será segregada da modalidade a distância? Ambas serão consideradas no momento da tomada de decisões? (FREIRE, 2018, p.148).

Pensar essas questões é essencial quando consideramos que a autoavaliação tem como função primordial a identificação dos pontos a serem aprimorados dentro da instituição.

Segue um quadro sobre a trajetória dos instrumentos avaliativos, a partir das informações disponibilizadas no site da Cavi, elaborado por Freire (2018) em sua dissertação:

Quadro 1 - Trajetória dos instrumentos de autoavaliação da UFG (2009-2018)

\begin{tabular}{|c|c|c|c|}
\hline & $\begin{array}{l}\text { Instrumentos que analisam } \\
\text { elementos da modalidade EaD }\end{array}$ & $\begin{array}{c}\text { Instrumentos que analisam } \\
\text { elementos da modalidade } \\
\text { presencial }\end{array}$ & $\begin{array}{l}\text { Características dos } \\
\text { instrumentos }\end{array}$ \\
\hline $\begin{array}{l}2009-2015 \\
\text { (50 ao } 70 \\
\text { ciclo } \\
\text { avaliativo) }\end{array}$ & $\begin{array}{l}\text { - Questionário a ser respondido } \\
\text { pelos estudantes de Graduação } \\
\text { na modalidade à distância } \\
\text { (exclusivo para alunos EaD). } \\
\text { - Questionário a ser respondido } \\
\text { pelos estudantes de Pós- } \\
\text { Graduação Lato Sensu na } \\
\text { modalidade à distância } \\
\text { (exclusivo para alunos EaD). }\end{array}$ & $\begin{array}{l}\text { - Roteiro de Entrevista do grupo } \\
\text { de enfoque Docentes e } \\
\text { Técnicos-Administrativos (não } \\
\text { engloba elementos de EaD). } \\
\text { - Roteiro de Entrevista do grupo } \\
\text { de enfoque Discente (não } \\
\text { engloba elementos de EaD). } \\
\text { - Roteiro da Entrevista do grupo } \\
\text { de enfoque da avaliação } \\
\text { externa } \\
\text { (não engloba elementos de } \\
\text { EaD). } \\
\text { - Questionário a ser respondido } \\
\text { pelas Unidades/Campi/Núcleos } \\
\text { (não engloba elementos de } \\
\text { EaD). } \\
\text { - Questionário a ser respondido } \\
\text { pelos estudantes do Centro de } \\
\text { Ensino e Pesquisa Aplicada à } \\
\text { Educação (Cepae) (não engloba } \\
\text { elementos de EaD). } \\
\text { - Questionário a ser respondido } \\
\text { pelos estudantes de Graduação } \\
\text { (não engloba elementos de } \\
\text { EaD). } \\
\text { - Questionário a ser respondido } \\
\text { pelos estudantes de Pós- } \\
\text { Graduação (não engloba } \\
\text { elementos de EaD). } \\
\text { - Instrumento on-line para } \\
\text { avaliação dos docentes pelos } \\
\text { estudantes (não engloba } \\
\text { elementos de EaD). }\end{array}$ & 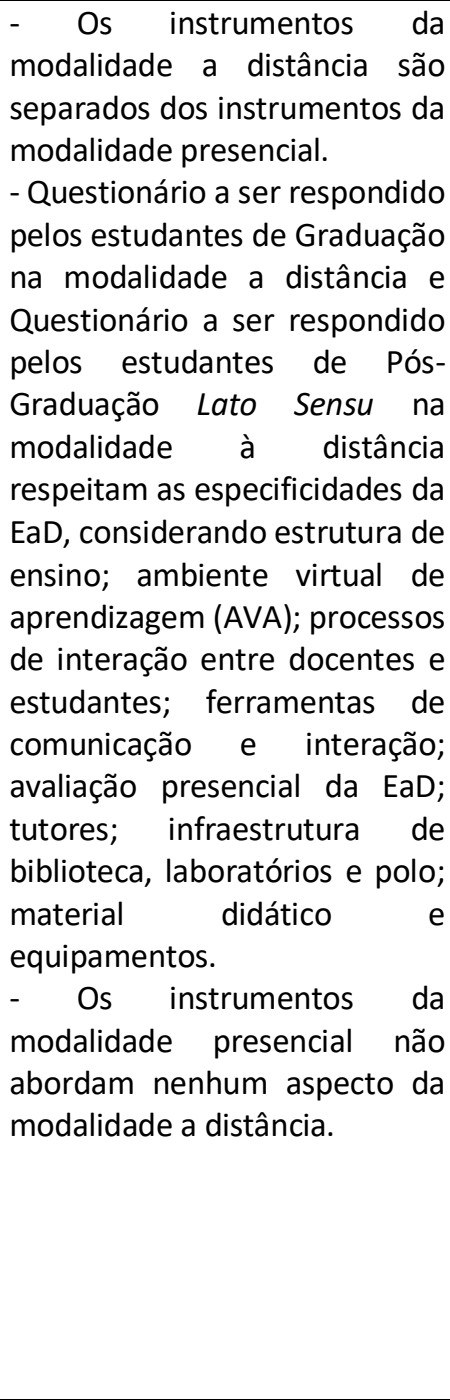 \\
\hline $\begin{array}{l}2016(80 \\
\quad \text { ciclo } \\
\text { avaliativo) }\end{array}$ & $\begin{array}{l}\text { - Instrumento de Autoavaliação } \\
\text { do Estudante (questionário } \\
\text { mistura elementos de EaD com }\end{array}$ & $\begin{array}{l}\text { - Instrumento de Autoavaliação } \\
\text { Institucional } 1 \text { (estudantes, } \\
\text { professores e érnico- }\end{array}$ & $\begin{array}{l}\text { - Os instrumentos da } \\
\text { modalidade a distância e da } \\
\text { modalidade presencial estão }\end{array}$ \\
\hline
\end{tabular}

Periódico Horizontes - USF - Itatiba, SP - Brasil - e021058 


\begin{tabular}{|c|c|c|c|}
\hline & H O R I Z O N T E S & (i) & $/ /$ doi.org/10.24933/horizontes.v39i1.937 \\
\hline & $\begin{array}{l}\text { elementos de presencial). } \\
\text { - Instrumento de Autoavaliação } \\
\text { do Estudante, em Libras } \\
\text { (questionário mistura } \\
\text { elementos de EaD com } \\
\text { elementos de presencial). } \\
\text { - Instrumento de Avaliação do } \\
\text { Docente pelos Estudantes } \\
\text { (questionário mistura } \\
\text { elementos de EaD com } \\
\text { elementos de } \\
\text { presencial). } \\
\text { - Instrumento de Avaliação do } \\
\text { Docente pelos Estudantes, em } \\
\text { Libras (questionário mistura } \\
\text { elementos de EaD com } \\
\text { elementos de presencial). }\end{array}$ & $\begin{array}{l}\text { administrativos) (não engloba } \\
\text { elementos de EaD) } \\
\text { - Instrumento de Autoavaliação } \\
\text { Institucional, em Libras (não } \\
\text { engloba elementos de EaD) } \\
\text { - Instrumento de Autoavaliação } \\
\text { do Estudante (questionário } \\
\text { mistura elementos de EaD com } \\
\text { presencial) } \\
\text { - Instrumento de Autoavaliação } \\
\text { do Estudante, em Libras } \\
\text { (questionário mistura } \\
\text { elementos de EaD com } \\
\text { elementos de presencial) } \\
\text { - Instrumento de Avaliação do } \\
\text { Docente pelos Estudantes } \\
\text { (questionário mistura } \\
\text { elementos de EaD com } \\
\text { elementos de presencial). } \\
\text { - Instrumento de Avaliação do } \\
\text { Docente pelos Estudantes, em } \\
\text { Libras mistura } \\
\text { (questionário com } \\
\text { elementos de EaD com } \\
\text { elementos de presencial) } \\
\text { - Instrumento de Avaliação da } \\
\text { Turma pelo Docente (não } \\
\text { engloba elementos de EaD) } \\
\text { - Instrumento de avaliação da } \\
\text { Turma pelo Docente, em Libras } \\
\text { (não engloba elementos de } \\
\text { EaD). }\end{array}$ & $\begin{array}{l}\text { inclusos mosmo } \\
\text { questionário: não há separação } \\
\text { entre as perguntas. } \\
\text { - Forte redução na dimensão } \\
\text { dos questionários de ambas as } \\
\text { modalidades - perguntas mais } \\
\text { curtas e em número menor. } \\
\text { - As questões que englobam } \\
\text { especificidades da modalidade } \\
\text { a distância dividem espaço com } \\
\text { as da modalidade presencial, } \\
\text { com alternativas que igualam } \\
\text { aulas e atividades de EaD, por } \\
\text { exemplo, como se ambas } \\
\text { possuíssem as mesmas } \\
\text { características. }\end{array}$ \\
\hline $\begin{array}{c}2017 \text { (8ㅇ } \\
\text { ciclo } \\
\text { avaliativo) }\end{array}$ & $\begin{array}{l}\text { - Instrumento de Autoavaliação } \\
\text { do Estudante mistura } \\
\text { (questionário EaD com } \\
\text { elementos de presencial) } \\
\text { elementos de prearo } \\
\text { - Instrumento de Autoavaliação } \\
\text { do Estudante, em Libras mistura } \\
\text { (questionário com } \\
\text { elementos de EaD cos com } \\
\text { elementos de presencial) } \\
\text { - Instrumento de Avaliação do } \\
\text { Docente pelos Estudantes } \\
\text { (questionário mistura } \\
\text { elementos de EaD com } \\
\text { elementos de presencial) } \\
\text { - Instrumento de Avaliação do } \\
\text { Docente pelos Estudantes, em } \\
\text { Libras mistura } \\
\text { (questionário com } \\
\text { elementos de EaD com } \\
\text { elementos de presencial). }\end{array}$ & $\begin{array}{l}\text { - Instrumento de Autoavaliação } \\
\text { Institucional } 1 \text { (estudantes, } \\
\text { professores e técnico- } \\
\text { administrativos) } \\
\text { (não engloba elementos de } \\
\text { EaD) } \\
\text { - Instrumento de Autoavaliação } \\
\text { Institucional } 2 \text { (professores e } \\
\text { técnico-administrativos) } \\
\text { (não engloba elementos de } \\
\text { EaD) } \\
\text { - Instrumento de Autoavaliação } \\
\text { do Estudante } \\
\text { (questionário } \\
\text { elementos de EaD com } \\
\text { elementos de presencial) } \\
\text { - Instrumento de Autoavaliação } \\
\text { do Estudante, em Libras } \\
\text { (questionário mistura } \\
\text { elementos de EaD com } \\
\text { elementos de presencial) } \\
\text { - Instrumento de Avaliação do }\end{array}$ & $\begin{array}{l}\text { - O Instrumento de } \\
\text { Autoavaliação Institucional } 2 \text { é } \\
\text { voltado apenas para } \\
\text { professores e técnico- } \\
\text { administrativos, relativo à } \\
\text { gestão e as condições de } \\
\text { trabalho, foi aplicado a partir de } \\
2017 \text {. } \\
\text { - Os instrumentos que analisam } \\
\text { a modalidade presencial não } \\
\text { tiveram mudança de } 2016 \text { para } \\
2017 \text {, com exceção da inserção } \\
\text { do Instrumento de } \\
\text { Autoavaliação Institucional } 2 \text {. } \\
\text { - Em relação aos instrumentos } \\
\text { que englobam elementos de } \\
\text { EaD, estes permaneceram os } \\
\text { mesmos de } 2016 \text {. Não houve } \\
\text { alteração dos aspectos da } \\
\text { modalidade a distância em } \\
\text { relação a 2016. }\end{array}$ \\
\hline
\end{tabular}




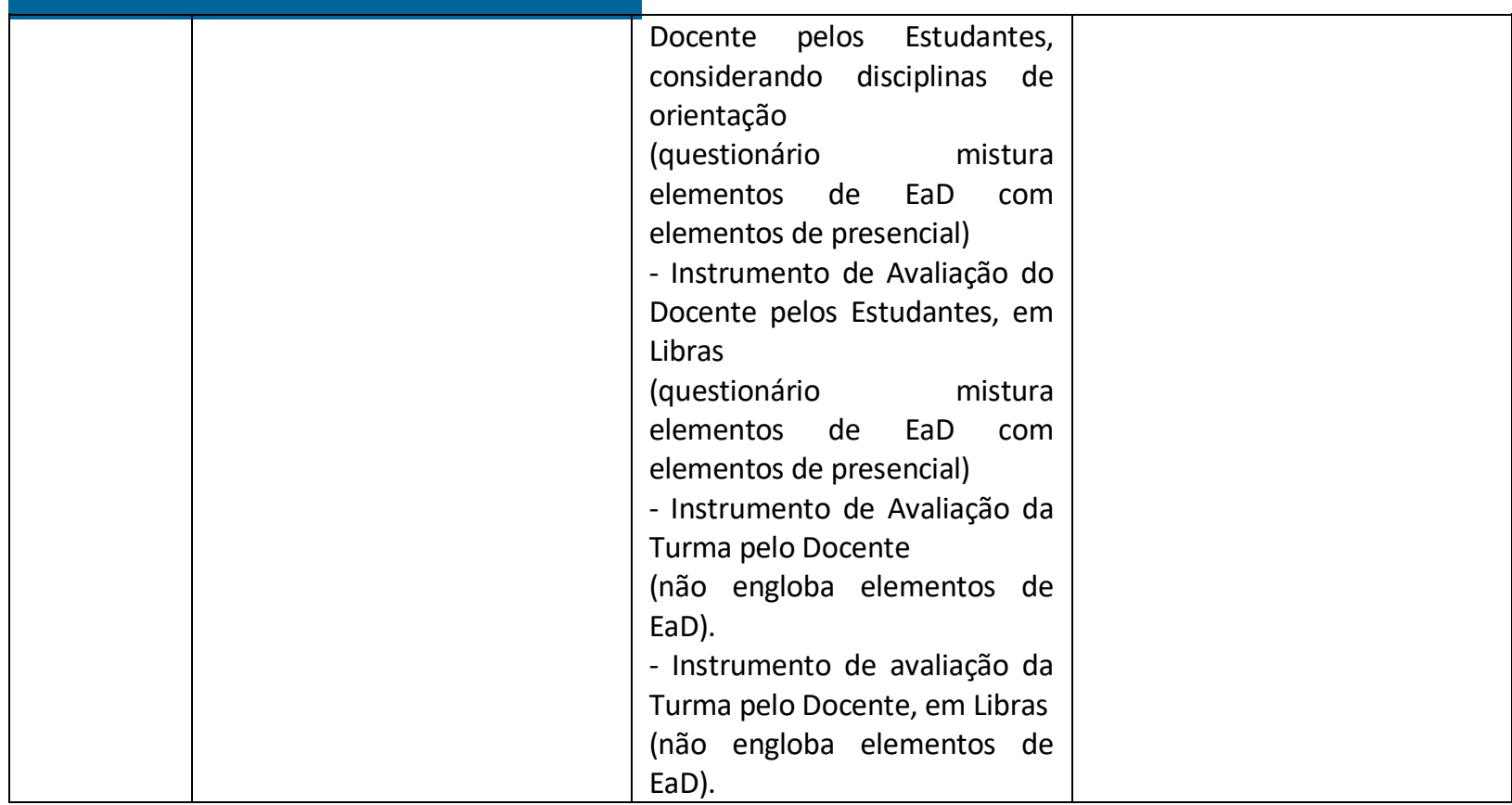

Fonte: Elaborado por Freire (2018), com base no Site da Cavi (UFG, 2016c).

Deste modo, ao analisar os instrumentos avaliativos e sua trajetória de 2009 a 2017, é possível constatar o quanto a educação a distância retrocedeu no âmbito da Universidade Federal de Goiás. Nos primeiros períodos de 2009 a 2015, as suas especificidades eram consideradas e respeitadas, já nos anos de 2016 e 2017, com as alterações, isso não ocorreu.

Como Peters (2004) defende, a EaD possui as especificidades que precisam ser levadas em consideração. Porém, com as mudanças nos ciclos e a junção da avaliação das modalidades presencial e a distância no ano de 2015 a 2017, as suas particularidades são ignoradas e, consequentemente, o levantamento de dados para o diagnóstico desse ensino na UFG, buscando melhorias em sua qualidade, é algo que se torna difícil de fazer.

\section{Conclusão}

Com o objetivo de identificar e discutir de que maneira a EaD, a partir dos instrumentos de autoavaliação, passou a ser representada na UFG, esta pesquisa foi realizada através de documentos disponibilizados pela Universidade no próprio site da Cavi e, anterior a isso, foi realizado um levantamento bibliográfico para compreender as perspectivas teóricas e estudos em relação ao tema. 
possível constatar o quanto a modalidade a distância não avançou e até mesmo retrocedeu, no sentido de representatividade, quando se considera o processo de autoavaliação da instituição. Nos instrumentos de 2009 a 2015, algumas especificidades da EaD foram respeitadas, como os aspectos pedagógicos, a equipe que atua no ensino e a infraestrutura nos polos. No entanto, é perceptível que isso não é suficiente para a integralização desta na Universidade.

Com as mudanças no ciclo avaliativo em 2015, os instrumentos de 2016 e 2017 sofreram alterações e a modalidade a distância, que antes tinha os seus próprios questionários, passou a ser avaliada junto à presencial, com atribuição apenas de notas ( 0 a 10) e pelo Portal UFGnet. Se no período anterior as particularidades da EaD foram consideradas, neste novo modelo de autoavaliação há uma visão simplista, reduzindo somente a questões que envolvam o comparecimento dos discentes nas aulas e chats, realização de atividades, disciplinas etc. No entanto, vale ressaltar que os chats não são as únicas ferramentas do ensino a distância, os ambientes virtuais de aprendizagem não são apenas para a realização de atividades e os próprios alunos da EaD, como nos afirmam Moore e Kearsley (2007), são diferentes, possuem aptidões para os estudos e contextos distintos dos alunos da modalidade presencial.

Entendendo que o objetivo maior da autoavaliação institucional é compreender as dinâmicas da instituição e, a partir disso, desenvolvê-la, como é possível que a modalidade a distância seja pensada se esta não encontra representatividade nos documentos de avaliação?

Sendo assim, é essencial que todos entendam que a educação a distância é uma modalidade de ensino que perpassa todos os níveis da educação e que possui as suas especificidades, particularidades e demandas. Logo, é importante que essas especificidades sejam respeitadas no âmbito das instituições de ensino superior.

Não obstante, durante a realização desta pesquisa e diante deste contexto, foi possível destacar alguns impasses que precisam ser analisados e repensados pela instituição, ficando como perspectivas para que sejam solucionados e, assim, aconteça uma melhoria na qualidade do ensino a distância. Constatou-se que na Comissão de Avaliação Institucional (Cavi), até 2018, existia apenas um representante da EaD para tomar as decisões. Por se tratar de uma modalidade de ensino, é necessário que tenha vários representantes para que se tenha um trabalho efetivo e que leve em consideração as suas particularidades. Além disso, na Portaria de nomeação publicada pela Cavi em seu site, não há definição das funções de cada membro, 
não de representantes.

No que diz respeito aos instrumentos, a autoavaliação não deveria envolver apenas os docentes, discentes e técnico-administrativos. Deveria englobar todos os que fazem parte do ensino a distância, como por exemplo, a tutoria dos polos, por ser um local de contato direto com o aluno. Além de tudo, como uma medida mais relevante, espera-se que a Universidade reveja o processo de autoavaliação da educação a distância junto ao da modalidade presencial, pensando as modalidades como dois contextos diferentes, que devem ser avaliados separadamente para que possam ser melhor compreendidos.

\section{Referências}

BRASIL. Ministério da Educação (MEC). Portaria no 2.117, de 06 de dezembro de 2019. Dispõe sobre a oferta, por Instituições de Educação Superior - IES, de disciplinas na modalidade a distância em cursos de graduação presencial. Brasília, DF: Presidência da República, Casa Civil, Subchefia para Assuntos Jurídicos, 2018. Disponível em: http://www.in.gov.br/materia//asset_publisher/Kujrw0TZC2Mb/content/id/57496468/do1-2018-12-31-portaria-n-1-428-de28-de-dezembro-de-2018-57496251. Acesso em: 29 jan.2019.

BRASIL. Ministério da Educação (MEC). Portaria no 1.428, de 28 de dezembro de 2018. Dispõe sobre a oferta, por Instituições de Educação Superior - IES, de disciplinas na modalidade a distância em cursos de graduação presencial. Brasília, DF: Presidência da República, Casa Civil, Subchefia para Assuntos Jurídicos, 2018. Disponível em: http://www.in.gov.br/materia//asset_publisher/Kujrw0TZC2Mb/content/id/57496468/do1-2018-12-31-portaria-n-1-428-de28-de-dezembro-de-2018-57496251. Acesso em: 29 jan.2019.

BRASIL. Decreto no 9.057, de 25 de maio de 2017. Regulamenta o art. 80 da Lei no 9.394, de 20 de dezembro de 1996, que estabelece as diretrizes e bases da educação nacional. Brasília, DF: Presidência da República, Casa Civil, Subchefia para Assuntos Jurídicos, 2017a. Disponível em: http://www.planalto.gov.br/ccivil_03/_Ato2015-2018/2017/Decreto/D9057.htm. Acesso em: 18 jul. 2018.

BRASIL. Ministério da Educação (MEC). Portaria Normativa no 11, de 20 de junho de 2017. Estabelece normas para o credenciamento de instituições e a oferta de cursos superiores a distância, em conformidade com o Decreto no 9.057, de 25 de maio de 2017. Brasília, DF: Presidência da República, Casa Civil, Subchefia para Assuntos Jurídicos, 2017b. Disponível em: http://portal.mec.gov.br/index.php?option=com_docman\&view=download\&alias=66431portaria-normativa-11-pdf\&category_slug=maio-2017-pdf\&ltemid=30192. Acesso em: 18 jul.2018. 
BRASIL. Ministério da Educação (MEC). Conselho

Nacional de Educação Câmara de Educação Superior. Resolução no 1, de 11 de março de 2016. Estabelece Diretrizes e Normas Nacionais para a Oferta de Programas e Cursos de Educação Superior na Modalidade a Distância. 2016. Disponível em: https://www.unesp.br/nead/Home/regulamentacao/07112016_ead_resolucao_n_1_11032016 .pdf. Acesso em: 18 jul. 2018.

BRASIL. Lei no 10.861, de 14 de abril de 2004. Institui o Sistema Nacional de Avaliação da Educação Superior - SINAES e dá outras providências. Brasília, DF: Presidência da República, Casa Civil, Subchefia para Assuntos Jurídicos, 2004. Disponível em: http://www.planalto.gov.br/ccivil_03/_ato2004-2006/2004/lei/l10.861.htm. Acesso em: 18 jul. 2018.

BRASIL. Lei no 9.394, de 20 de dezembro de 1996. Estabelece as diretrizes e bases da educação nacional. Lei de Diretrizes e Bases da Educação - LDB. Brasília, 1996. Disponível em: http://www.planalto.gov.br/ccivil_03/Leis/L9394.htm. Acesso em: 18 jul. 2018.

DEPRESBITERIS, L. Auto-avaliação das instituições de ensino superior. Estudos em Avaliação Educacional, v.16, n.32, p.7-24, 2005. Disponível em: http://publicacoes.fcc.org.br/ojs/index.php/eae/article/view/2133. Acesso em: 18 jul. 2018.

FREIRE, F. M. Trajetória e mecanismos da autoavaliação institucional de cursos da modalidade a distância na Universidade Federal de Goiás. 206 p. Dissertação (Mestrado em Educação) Universidade Federal de Goiás, 2018.

GALDINO, M. N. D. A autoavaliação institucional no ensino superior como instrumento de gestão. Rio de Janeiro: Fundação Cesgranrio/Universidade do Grande Rio, 2011. Disponível em: http://unigranrio.com.br/_docs/cpa/autoav-inst-ensino-sup-instr-gestao-mary-galdino.pdf. Acesso em: 18 jul. 2018.

INSTITUTO NACIONAL DE ESTUDOS E PESQUISAS EDUCACIONAIS ANÍSIO TEIXEIRA - INEP. Sinopse estatística da educação superior 2018. Brasília: Inep.2019. Disponível em http://portal.inep.gov.br/web/guest/sinopses-estatisticas-da-educacao-superior. Acesso em 30 dez. 2019.

LAKATOS, E. M.; MARCONI, E. M.. Fundamentos de metodologia científica. 5. ed. São Paulo: Atlas, 2003.

LIMA, D. C. B. P. Produto 02 - documento técnico contendo estudo analítico do processo de expansão de EaD ocorrido no período 2002-2012, particularmente no que se refere aos cursos de formação de professores nas IES públicas e privadas. Projeto Conselho Nacional de Educação/UNESCO de Desenvolvimento, aprimoramento e consolidação de uma educação nacional de qualidade - Educação a distância na educação superior. 2014. Disponível em: http://portal.mec.gov.br/index.php?option=com_docman\&view=download\&alias=16511produto-02-estudo-processo\&Itemid=30192. Acesso em: 18 jul. 2018. 
Prentice Hall, 2007.

MOORE, M. G.; KEARSLEY, G. Educação a distância: uma visão integrada [Edição especial da Associação Brasileira de Educação a Distância (Abed)]. São Paulo: Thomson Learning, 2007.

PETERS, O. A educação a distância em transição. Trad. Ilson Kayser. São Leopoldo: Editora Unisinos, 2004.

POLIDORI, M. M; MARINHO-ARAUJO, C. M.; BARREYRO, G. B. Sinaes: perspectivas e desafios na avaliação da educação superior brasileira. Educação, Rio de Janeiro, v.14, n.53, p.425-436, out./dez. 2006.

SILVA, E. L; MENEZES, E. M. Metodologia da pesquisa e elaboração de dissertações.

Florianópolis: Laboratório de Ensino a Distância da UFSC, 2001.

SOBRINHO, J. D. Avaliação e transformações da educação superior brasileira (1995-2009): do Provão ao Sinaes. Revista da Avaliação da Educação Superior. São Paulo, v.15, n.1, p.195-224, mar. 2010. Disponível em:

https://www.scielo.br/j/aval/a/SkVnKQhDyk6fkNngwvZq44c/abstract/?lang=pt. Acesso em: 18 jul. 2018.

SOBRINHO, J. D. Qualidade, avaliação: do SINAES a índices. Avaliação, Campinas/Sorocaba, v.13, n.3, p.817-825, nov.2008. Disponível em:

http://www.redalyc.org/pdf/2191/219114874011.pdf. Acesso em: 18 jul. 2018.

SOUZA, W. C.; BORGES, L. C.; LIMA, D. C. B. P. Levantamento bibliográfico sobre a autoavaliação institucional na educação a distância. In: SANTOS, C. A.; LIMA, D. C. B. P.; NOGUEIRA, D. X. P. (org.). Institucionalização da educação superior a distância nas universidades federais da região Centro-Oeste: temáticas em questão. Brasília, DF: Editora da UnB, 2021, p.255-268.

UFG. Comissão de Avaliação Institucional (Cavi). Instrumentos de avaliação. 2017a. Disponível em: https://cavi.prodirh.ufg.br/p/742-instrumentos-de-avaliacao. Acesso em: 18 jul.2018.

UFG. Comissão de Avaliação Institucional (Cavi). Projeto de avaliação institucional da UFG. 2017b. Disponível em: https://cavi.prodirh.ufg.br/n/5447-projeto-de-avaliacao-institucionalufg. Acesso em: 15 set. 2017.

UFG. Comissão de Avaliação Institucional (Cavi). Portaria no 5.126, de 6 de setembro de 2016. Revogar os termos da portaria no 3815, para designar uma comissão com a finalidade de dar continuidade aos trabalhos da CPA/CAVI. 2016a. Disponível em:

https://cavi.prodirh.ufg.br/up/65/o/Portaria-Cavi-2016.pdf. Acesso em: 18 jul. 2018.

UFG. Comissão de Avaliação Institucional (Cavi). Relatório [parcial] de avaliação institucional da UFG: 2015-2017. 2016b. Disponível em: https://cavi.prodirh.ufg.br/up/65/o/RAl_20152017_Parcial_2015_Atualizado.pdf. Acesso em: 18 jul. 2018. 
UFG. Comissão de Avaliação Institucional (Cavi). Projeto de avaliação institucional: renovação e integração. 2016c. Disponível em: https://cavi.prodirh.ufg.br/up/65/o/Novo_Projeto_Al_.pdf. Acesso em:18 jul. 2018.

UFG. Comissão de Avaliação (Cavi). Resolução Consuni no 14/2009. Alterar a Resolução Consuni no 01/2005, que cria a Comissão Própria de Avaliação - CPA, da UFG e dá outras providências. 2009. Disponível em:

https://cavi.prodirh.ufg.br/up/65/o/Resolucao_CONSUNI_2009_0014.pdf. Acesso em: 18 jul. 2018.

Recebido em fevereiro 2020.

Aprovado em agosto 2021. 